\title{
Determinants of Delay in Malaria Prompt Diagnosis and Timely Treatment among Under-Five Children in Shashogo Woreda, Hadiya Zone, Southern Ethiopia: A Case Control Study
}

\author{
Ermias Abera Turuse ${ }^{1 *}$, Kassahun Alemu Gelaye ${ }^{2}$, Teresa Kisi Beyen ${ }^{3}$ \\ ${ }^{1}$ Department of Nursing, Hossana College of Health Sciences, Hossana, Ethiopia \\ ${ }^{2}$ Department of Environmental and Occupational Health and Safety, Institute of Public Health, College of \\ Medicine and Health Science, University of Gondar, Gondar, Ethiopia \\ ${ }^{3}$ Department of Epidemiology and Biostatistics, Institute of Public Health, College of Medicine and Health \\ Science, University of Gondar, Gondar, Ethiopia \\ Email: ermiasturuse@gmail.com, alemukass@yahoo.com, terek7@gmail.com
}

Received 18 February 2014; revised 26 March 2014; accepted 4 April 2014

Copyright (C) 2014 by authors and Scientific Research Publishing Inc.

This work is licensed under the Creative Commons Attribution International License (CC BY). http://creativecommons.org/licenses/by/4.0/

(c) (i) Open Access

\section{Abstract}

Background: Ensuring prompt diagnosis and timely malaria treatment will prevent most cases of uncomplicated malaria from progressing to severe and fatal illness. To avoid this progression, treatment must begin as soon as possible, generally within 24 hours after symptoms onset. The reason why mothers/caretakers delay in malaria prompt diagnosis and timely treatment for under-five is not well studied in the study area as well as in Ethiopia. Objective: To assess determinants of delay in malaria prompt diagnosis and timely treatment among under-five children in Shashogo Woreda, Hadiya Zone, Southern Ethiopia, 2013. Methods: An unmatched case control study was conducted from March 25-April 25, 2013. A total sample size of 302 with 151 cases and 151 controls were selected by systematic random sampling techniques. Cases were under-five children who had clinical malaria and sought treatment after 24 hours of symptoms onset, and controls were under-five children who had clinical malaria and sought treatment within 24 hours of symptoms onset. Both bivariate and multivariate logistic regressions were done to identify determinant of delay in malaria prompt diagnosis and timely treatment. Results: A total of $\mathbf{1 5 1}$ mothers/caretakers of cases and 151 mothers/caretakers of controls were interviewed. Illiterate mothers $(\mathrm{AOR}=7.14 ; 95 \% \mathrm{CI}: 1.10,46.39)$, monthly income $\leq 500$ ETB $(\mathrm{AOR}=5.49 ; 95 \% \mathrm{CI}: 2.09$,

\footnotetext{
"Corresponding author.
}

How to cite this paper: Turuse, E.A., et al. (2014) Determinants of Delay in Malaria Prompt Diagnosis and Timely Treatment among Under-Five Children in Shashogo Woreda, Hadiya Zone, Southern Ethiopia: A Case Control Study. Health, 6, $950-959$. http://dx.doi.org/10.4236/health.2014.610120 
14.45), females sex $(\mathrm{AOR}=3.45 ; 95 \% \mathrm{CI}: 1.62,7.34)$, distance from health facility $>5 \mathrm{~km}(\mathrm{AOR}=$ 4.31; 95\%CI: 1.22, 15.23), absence of history of child death (AOR $=4.21$; 95\%CI: 1.514, 11.68), side effects of antimalarial drugs $(\mathrm{AOR}=2.91 ; 95 \% \mathrm{CI}: 1.15,7.33)$ and khat chewing $(\mathrm{AOR}=2.38 ; 95 \% \mathrm{CI}$ : $1.28,5.79)$ were determinants of delay in malaria prompt diagnosis and timely treatment of under-five children. Conclusion: Mother's education, monthly income, distance from health facility, absence of history of child death, complained about side effects of drugs and khat chewing were predictors of delay of prompt diagnosis and timely malaria treatment. Effective malaria control programs revision would be required to avoid delay of prompt diagnosis and timely treatment for under-five children.

\section{Keywords}

\section{Prompt Diagnosis, Timely Treatment, Children}

\section{Introduction}

Malaria is an important cause of death and illness in children and adults. Malaria control requires an integrate approach, including prevention (mainly vector control) and prompt treatment with effective antimalarial drugs [1] [2].

According to the world malaria report 2011, there are 106 malaria-endemic countries and approximately half the world's population is at risk for infection, worldwide. Malaria is a contributing cause of death for children, who represent $85 \%$ of all malaria deaths. Children are at risk because they lack developed immune systems to protect against the disease [3] [4].

Among death due to malaria occurring in Africa more than $90 \%$ are in under-five children that consequences in brain damage. Overall, malaria constitutes $10 \%$ of the continent's disease challenge [5] [6]. Prompt and timely treatment of malaria within 24 hours of the onset of symptoms is important to prevent life-threatening complications [7]. Poor, rural families in Sub-Saharan countries are less likely to have access to the preventative measures that are basic to malaria control, and may live many kilometers away from the health facility [8] [9].

Malaria is a major public health problem in Ethiopia and has been consistently reported as one of the three leading causes of morbidity and mortality. About 52 million people (68\%) live in malaria risk areas in Ethiopia mainly at altitudes below 2000 meters [10] [11]; it contributes up to 20\% of under-five deaths. However, most malaria deaths can be prevented when clinical cases are promptly diagnosed and timely treated [12].

To decrease mortality from febrile illnesses, sick children not merely need to get effective and appropriate drugs, but also need to bring them in time. At the Roll Back Malaria summit in Abuja in 2000, the heads of nation devoted themselves to ensure that by 2005 to $60 \%$ and by 2010 to $80 \%$ of those suffering from malaria should have correct, affordable and appropriate treatment within 24 hours of signs and symptoms onset [13] [14].

Ensuring prompt and timely treatment will prevent most cases of uncomplicated malaria from progressing to severe and fatal illness. To avoid this progression, treatment must begin as soon as possible, generally within 24 hours after symptoms onset. Communities would be aware of the importance of seeking prompt diagnosis and treatment [6].

Information concerning determinants of delay in malaria prompt diagnosis and timely treatment in under-five children is insufficient in study area as well as Ethiopia. Therefore, identifying determinants of delay in malaria prompt diagnosis and timely treatment in under-five children can help to reduce the morbidities and mortalities of malaria. Particularly, it would have a substantial contribution in the improvement of the health status of children and achieve the Millennium Development Goal number four.

\section{Methods}

\subsection{Study Design and Area}

To assess determinants of delay in malaria prompt diagnosis and timely treatment among under-five children in 
Shashogo woreda, Hadiya zone, Southern Ethiopia, Institution based unmatched case control study was conducted from March 25 to April 25, 2013. Shashogo woreda is one of the 10 woreda in the Hadiya zone and found at high risk of malaria transmission area with 123,602 total populations. It is located at $224 \mathrm{~km}$ from Addis Ababa, and 125 from the capital of region, Hawassa. The altitude of the woreda is below $1500 \mathrm{~m}$, and above $36 \%$ of climatic condition is kola.

\subsection{Source and Study Population}

Sample was obtained from all under-five children who came to health centers for malaria treatment. Under-five children who had one or more signs/symptoms of malaria and confirmed by microscope or rapid diagnosis test and sought treatment in the health centers after 24 hours of symptoms onset were considered as cases where as those who had one or more signs/symptoms of malaria and confirmed by microscope or rapid diagnosis test and sought treatment in the health centers within 24 hours of symptoms onset were considered as controls. However, severely ill children and neonates were not included in the study.

\subsection{Sample Size and Sampling Procedure}

The sample size was calculated by two population proportion formula for unmatched case control study design using Epi-Info version 3.5.3 statistical software by considering 35.5\% proportion of individuals travelling a distance of three kilometers or more to reach health facility among controls as an exposure variable and odds ratio of 2.01 from study conducted in south-west Ethiopia [15], 95\% confidence level, 80\% power of the study, 1:1 case to control ratio, $5 \%$ maximum acceptable difference and $5 \%$ non response rate. The final total sample size considered was 302 children (151 cases and 151 controls). Five health centers (Bonosha, Doesha, Jammaya, Hirko, and Shamo Ajacho) were included in the study. Study subject was selected by using systematic random sampling techniques by observing patient history card and laboratory request, and when patient was positive for any species of plasmodium, they were eligible and they moved to private room for interview until the total required sample size was obtained. Sampling frames were prepared for cases and controls separately for each health centers. Starting from the first participant selected by random selection procedures ( 1 to $\mathrm{K}^{\text {th }}$ by lottery method) from the first interval, every $\mathrm{K}^{\text {th }}$ individuals in the succeeding intervals (sampling interval) were selected proportionally based on catchment areas' under-five populations from each health center. Accordingly 82 (41 case and 41 control), 50 (25 case and 25 control), 60 (30 case and 30 control), 50 (25 case and 25 control), and 60 (30 case and 30 control) from Bonosha, Doesha, Jammaya, Hirko, and Shamo Ajacho were selected respectively. Please see Figure 1 below, it is clearly elaborated.

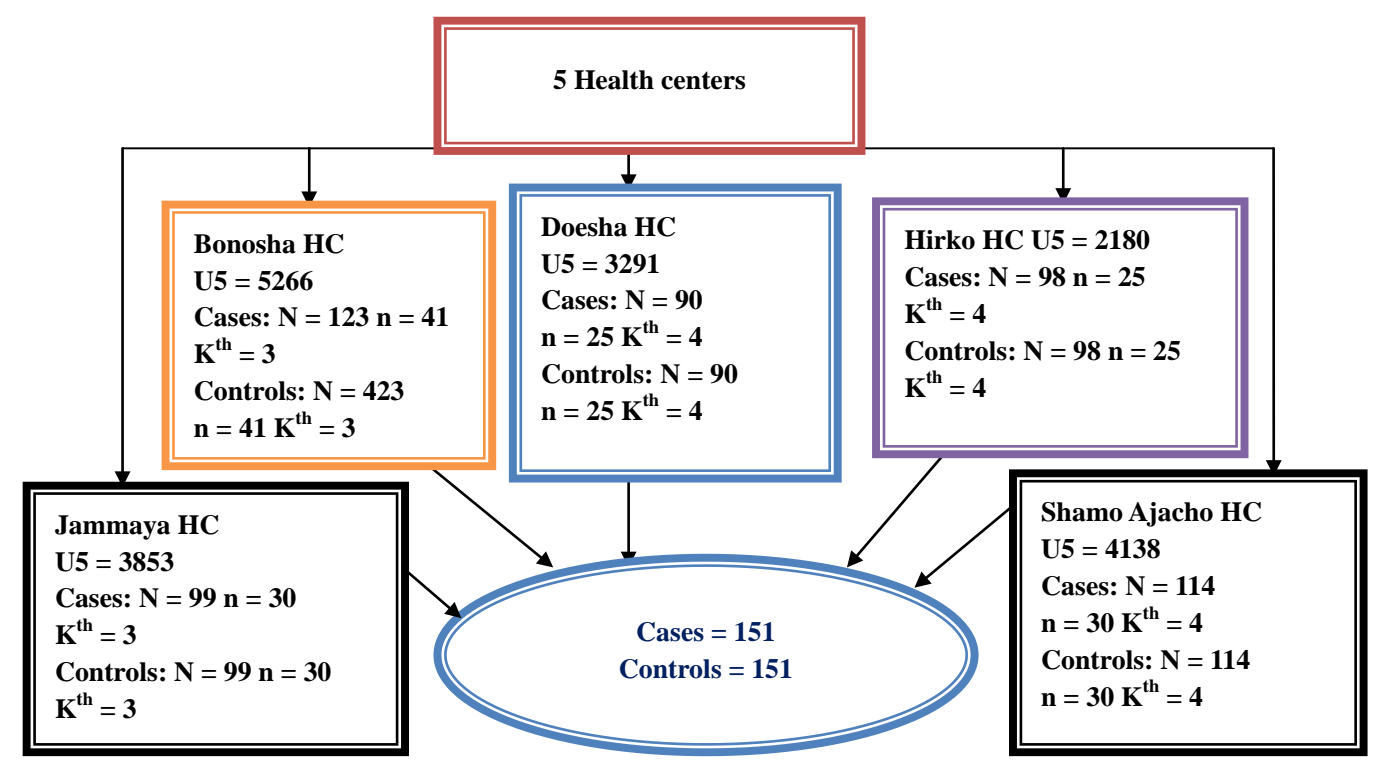

Figure 1. Schematic presentation of sampling technique for determinant of delay in malaria prompt diagnosis and timely treatment among under-five children in Shashogo woreda, March 2013. 


\subsection{Data Collection Procedures}

Data on delay in malaria prompt diagnosis and timely treatment, socio demographic characteristics, environmental factors, physical accessibility factors and behavioral factors were collected using interview aided, structured and pre-tested questionnaire which was developed by reviewing literature. The questionnaire was prepared originally in English and translated to Hadiyissa (local language) and back to English by language experts to keep the consistency of the questions. Training for data collectors and supervisors was made to ensure the quality of data. The questionnaire was pre-tested to identify potential problem of the questionnaires, unanticipated interpretations and cultural objections to any of questions on 15 (5\%) of respondents from Hachemo health center, which was not include in the actual study population before the actual data collection takes place. Based on the pre test results, the questionnaire was additionally adjusted contextually and terminologically, reliability analysis was done and 0.73 cronbach's alpha was obtained, and finally data were collected from whole sample. Counter checking of daily filled questionnaire and regular supervision were made by supervisor and the investigators.

\subsection{Data Processing and Data Analysis}

After data collection, each questionnaire was checked for competence and code was given before data entry. Data was cleaned and entered into EPI Info version 3.5.3 and then analysis was done using SPSS version 20. Descriptive statistics like frequency tables, graphs, percentages, means and standard deviations were used to describe the study variables. Bivariate logistic regression analysis was conducted primarily to check determinant factors of delay in malaria prompt diagnosis and timely treatment. Variables which found to be significant at 0.2 p-values in bivariate analysis were then interred into forward multivariate logistic regression analysis to control the effect of confounders and determinant factors in malaria prompt diagnosis and timely treatment were identifies using adjusted odds ratios with their 95\% confidence intervals and 0.05 p-values. The fitness of the model was tested by Hosmer and Lemeshow’s goodness-of-fit test and yielded p-value greater than 0.05.

\subsection{Ethical Consideration}

The study was carried out after getting permission from the ethical review board of institute of public health, university of Gondar. Then, an informed consent was obtained from each health institutions and parents of the under five children. Those parents who refused to participate in the study were not forced. Each parent was informed about the objective of the study. Confidentiality was granted for information collected by keeping the privacy of the respondents while filling the questionnaire, and giving codes for each questionnaire.

\section{Results}

\subsection{Socio Demographic Characteristics}

A total of 302 respondents were included in the study giving 100\% response rate. More than half of respondents were females for both cases, 87 (57.6\%) and controls, 105 (69.5\%). The mean age of cases was 33.12 years with 6.41 years standard deviation where as 27.72 years with 4.74 years standard deviation for controls. Most of the respondents were protestant Christian, 75 (49.7\%) cases and 96 (63.6\%) controls and most of the respondents were Hadiya in ethnicity, 112 (74.2\%) cases and 121 (80.1\%) controls in ethnic group. Over half of the participants in both cases, 98 (64.9\%) and controls, 135 (89.4\%) had monogamy marriage type. Most of children were females, 101 (66.9\%), in the cases while males, 108 (71.5\%), in the controls. The mean age of cases was 25.06 months with 12.37 months standard deviation and controls were 18.22 months with 10.85 months standard deviation.

Sixty three (41.7\%) cases' mothers were illiterate where as only 15 (9.9\%) for controls. On the other hand 25 (16.6\%) of fathers attended secondary school for cases whereas 77 (51.0\%) for controls. Most of the cases' mothers, 116 (76.8\%), and 79 (52.3\%) controls' were housewives. The main paternal occupations were farming, 97 (64.2\%) cases’ fathers and 55 (36.4\%) controls’ fathers, and governmental employed, 17 (11.3\%) cases’ fathers and 60 (39.7\%) controls' fathers. Parents whose average monthly income was less than or equal to 500 ETB were 88 (58.3\%) for cases and 19 (12.6\%) for controls (Table 1). 
Table 1. Socio-demographic characteristics of respondents in Shashogo woreda, Hadiya zone, Southern Ethiopia, May 2013 $(\mathrm{n}=302)$.

\begin{tabular}{|c|c|c|c|}
\hline Variables & $\begin{array}{c}\text { Cases }(\mathrm{n}=151) \\
\text { number }(\%)\end{array}$ & $\begin{array}{c}\text { Controls }(n=151) \\
\text { number }(\%)\end{array}$ & $\begin{array}{c}\text { Total } \\
\text { number (\%) }\end{array}$ \\
\hline \multicolumn{4}{|l|}{ Sex respondents } \\
\hline Female & 87 (57.6\%) & 105 (69.5\%) & 192 (63.6\%) \\
\hline Male & 64 (42.4\%) & 46 (30.5\%) & 110 (36.4\%) \\
\hline \multicolumn{4}{|l|}{ Age of respondents } \\
\hline $20-29$ & 48 (31.8\%) & 98 (64.9\%) & $146(48.3 \%)$ \\
\hline $30-39$ & 73 (48.3\%) & $42(27.8)$ & 115 (38.1\%) \\
\hline $40-49$ & 30 (19.9\%) & $11(7.3 \%)$ & 41 (13.6\%) \\
\hline \multicolumn{4}{|l|}{ Religions } \\
\hline Protestant & 75 (49.7\%) & $96(63.6 \%)$ & $171(56.6 \%)$ \\
\hline Orthodox & $22(14.6 \%)$ & 22 (14.6\%) & 44 (14.6\%) \\
\hline Muslim & 53 (35.1\%) & 32 (21.2\%) & $85(28.1 \%)$ \\
\hline Others & $1(0.7 \%)$ & $1(0.7 \%)$ & $2(0.7 \%)$ \\
\hline \multicolumn{4}{|l|}{ Ethnic group } \\
\hline Hadiya & 112 (70.9\%) & $121(80.1 \%)$ & $233(77.2 \%)$ \\
\hline Silte & 22 (14.6\%) & $16(10.6 \%)$ & 38 (12.6\%) \\
\hline Gurage & $7(4.6 \%)$ & $6(4.0 \%)$ & $13(4.3 \%)$ \\
\hline Amhara & 7 (4.6\%) & $7(4.6 \%)$ & $14(4.6 \%)$ \\
\hline Others & $3(2.0 \%)$ & $1(0.7 \%)$ & $4(1.3 \%)$ \\
\hline \multicolumn{4}{|l|}{ Residences } \\
\hline Rural & $126(83.4 \%)$ & $105(69.5 \%)$ & 231 (76.5\%) \\
\hline Urban & 25 (16.6\%) & 46 (30.5\%) & $71(23.5 \%)$ \\
\hline \multicolumn{4}{|l|}{ Marriage types } \\
\hline Polygamy & 53 (33.8\%) & $16(9.3 \%)$ & 69 (22.8\%) \\
\hline Monogamy & 98 (64.9\%) & 135 (89.4\%) & $233(77.2 \%)$ \\
\hline \multicolumn{4}{|l|}{ Family size } \\
\hline$\leq 3$ & $20(13.2 \%)$ & 30 (19.9\%) & $50(16.6 \%)$ \\
\hline $4-6$ & 77 (51.0\%) & $82(54.3 \%)$ & 159 (52.6\%) \\
\hline$>6$ & 54 (35.8\%) & 39 (25.8\%) & 93 (30.8\%) \\
\hline \multicolumn{4}{|l|}{ Age of children/M } \\
\hline $1-12$ & 44 (29.1\%) & 58 (38.4\%) & 102 (33.8\%) \\
\hline $13-24$ & 48 (31.8\%) & $56(37.1 \%)$ & 104 (34.4\%) \\
\hline$>24$ & 59 (39.1\%) & 37 (24.5\%) & 96 (31.8\%) \\
\hline \multicolumn{4}{|l|}{ Sex of children } \\
\hline Female & $101(66.9 \%)$ & 43 (28.5\%) & 144 (47.7\%) \\
\hline Male & 50 (33.1\%) & 108 (71.5\%) & 158 (52.3\%) \\
\hline \multicolumn{4}{|l|}{ Mother's education } \\
\hline Illiterate & $63(41.7 \%)$ & 15 (9.9\%) & 78 (25.8\%) \\
\hline Read and write & 36 (23.8\%) & 8 (5.3\%) & 44 (14.6\%) \\
\hline Primary school & 34 (22.5\%) & 31 (20.5\%) & 65 (21.5\%) \\
\hline Secondary school & $16(10.6 \%)$ & $84(55.6 \%)$ & 100 (33.1\%) \\
\hline Above secondary & $2(1.3 \%)$ & $13(8.6 \%)$ & $15(5.0 \%)$ \\
\hline
\end{tabular}




\section{Continued}

\begin{tabular}{|c|c|c|c|}
\hline \multicolumn{4}{|l|}{ Father's education } \\
\hline Illiterate & 46 (30.5\%) & $12(7.9 \%)$ & $58(19.2 \%)$ \\
\hline Read and write & 29 (19.2\%) & $5(3.3 \%)$ & 34 (11.3\%) \\
\hline Primary school & 39 (25.8\%) & $11(7.3 \%)$ & $50(16.6 \%)$ \\
\hline Secondary school & $25(16.6 \%)$ & 77 (51.0\%) & $102(33.8 \%)$ \\
\hline Above secondary & $12(7.9 \%)$ & 46 (30.5\%) & 58 (19.2\%) \\
\hline \multicolumn{4}{|l|}{ Mother's occupation } \\
\hline House wife & $116(76.8 \%)$ & 79 (52.3\%) & 195 (64.6\%) \\
\hline Gov’t employee & $8(5.3 \%)$ & 46 (30.5\%) & $54(17.9 \%)$ \\
\hline NGO employee & $4(2.6 \%)$ & $9(6.0 \%)$ & $13(4.3 \%)$ \\
\hline Merchant & $23(15.2 \%)$ & 17 (11.3\%) & $40(13.2 \%)$ \\
\hline \multicolumn{4}{|l|}{ Father's occupation } \\
\hline Farmers & 97 (64.2\%) & 55 (36.4\%) & $152(50.3 \%)$ \\
\hline Gov't employee & 17 (11.3\%) & 60 (39.7\%) & 77 (25.5\%) \\
\hline NGO employee & $2(1.3 \%)$ & $12(7.9 \%)$ & $14(4.6 \%)$ \\
\hline Merchant & 35 (23.2\%) & $24(15.9 \%)$ & 59 (19.5\%) \\
\hline \multicolumn{4}{|l|}{ Average monthly income } \\
\hline$\leq 500$ & 88 (58.3\%) & 19 (12.6\%) & $107(35.4 \%)$ \\
\hline $501-999.9$ & $26(17.2 \%)$ & $32(21.2 \%)$ & 58 (19.2\%) \\
\hline$\geq 1000$ & 37 (24.5\%) & $100(66.2 \%)$ & $137(45.4 \%)$ \\
\hline
\end{tabular}

\subsection{Behavioral and Physical Accessibility Factors}

A total of 41 (27.2\%) and 14 (9.3\%) mothers/caretakers of cases and controls were distrusting the health care providers respectively. A total of $61(40.4 \%)$ cases' and 22 (14.6\%) controls' parents/caretakers had alcohol drinking behavior. Out of these 49 (32.5\%) were cases' fathers and 20 (13.2\%) were controls' fathers. A total 78 (51.7\%) cases' and 22 (14.6\%) controls' parents were chewing khat, of which 39 (25.5\%) were cases' and 9 (6.0\%) controls' fathers. Most of the mothers/caretakers didn't fear treatment cost when child became sick. A total of $48(15.9 \%)$ respondents had history of under-five children death, from which 19 (12.6\%) were from cases and 29 (19.2\%) were from controls. Most of the mothers/caretakers didn't fear the side effect of antimalarial drugs.

Most of the mothers/caretakers of both cases, 127 (84.1\%) and controls, 141 (93.4\%) had good knowledge about malaria prevention and control methods. Majority of respondents, 98 (64.9\%) of cases came to health centers from 4 - $5 \mathrm{~km}$ while most, 117 (77.5\%), of the controls came from $3 \mathrm{~km}$. Most of respondents of both cases, 104 (68.9\%), and controls, 121 (80.1\%), came to health centers by foot (Table 2).

\subsection{Determinants of Delay in Malaria Prompt Diagnosis and Timely Treatment}

After conducting both bivariate and multivariate logistic regression mothers' education, monthly income, sex of child, distance from health facility, absence of history of child death, complain about side effects of drugs and khat chewing were identified as predictors of delay of prompt diagnosis and timely malaria treatment for under five children (Table 3).

\section{Discussion}

This study attempted to identify determinant factors of delay in malaria prompt diagnosis and timely treatment in under-five children. Mother's education, average monthly income, sex of child, distance from health centers, absence of history of child death, complain about side effect of antimalarial drugs and khat chewing were predictors of delay in malaria prompt diagnosis and timely treatment. 
Table 2. Behavioral and physical accessibility factors related to delay of prompt malaria diagnosis and timely treatment among under-five children in Shashogo woreda, Hadiya zone, Southern Ethiopia, May 2013 (n = 302).

\begin{tabular}{|c|c|c|c|}
\hline Variables & $\begin{array}{c}\text { Cases }(\mathrm{n}=151) \\
\text { number }(\%)\end{array}$ & $\begin{array}{c}\text { Controls }(\mathrm{n}=151) \\
\text { number }(\%)\end{array}$ & $\begin{array}{c}\text { Total } \\
\text { number }(\%)\end{array}$ \\
\hline \multicolumn{4}{|l|}{ Knowledge } \\
\hline Good & $127(84.1 \%)$ & 141 (93.4\%) & 268 (88.7\%) \\
\hline Poor & $24(15.9 \%)$ & $10(6.6 \%)$ & $34(11.3 \%)$ \\
\hline \multicolumn{4}{|l|}{ Distance } \\
\hline$\leq 3 \mathrm{~km}$ & 31 (20.5\%) & 117 (77.5\%) & 148 (49.0\%) \\
\hline $4-5 \mathrm{~km}$ & 98 (64.9\%) & $22(14.6 \%)$ & 120 (39.7\%) \\
\hline$>5 \mathrm{~km}$ & 22 (14.6\%) & $12(7.9 \%)$ & 34 (11.3\%) \\
\hline \multicolumn{4}{|l|}{ Transport system } \\
\hline Foot & $104(68.9 \%)$ & $121(80.1 \%)$ & 225 (74.5\%) \\
\hline Horse back & $39(25.8 \%)$ & $21(13.9 \%)$ & 60 (19.9\%) \\
\hline Car & $8(5.3 \%)$ & $9(6.0 \%)$ & $17(5.6 \%)$ \\
\hline \multicolumn{4}{|c|}{ History of child death } \\
\hline Yes & $19(12.6 \%)$ & $29(19.2 \%)$ & 48 (15.9\%) \\
\hline No & $132(87.4 \%)$ & $122(80.8 \%)$ & 254 (84.1\%) \\
\hline \multicolumn{4}{|l|}{ Fear of side effect } \\
\hline Yes & $54(35.8 \%)$ & $32(21.2 \%)$ & $86(28.5 \%)$ \\
\hline No & 97 (64.2\%) & $119(78.8 \%)$ & $216(71.5 \%)$ \\
\hline \multicolumn{4}{|c|}{ Distrust health providers } \\
\hline Yes & $41(27.2 \%)$ & $14(9.3 \%)$ & 55 (18.2\%) \\
\hline No & $110(72.8 \%)$ & 137 (90.7\%) & $247(81.8 \%)$ \\
\hline \multicolumn{4}{|l|}{ Alcohols drinkers } \\
\hline Yes & $61(40.4 \%)$ & $22(14.6 \%)$ & $83(27.5 \%)$ \\
\hline No & 90 (59.6\%) & $129(85.4 \%)$ & 219 (72.5\%) \\
\hline \multicolumn{4}{|l|}{ Who drink alcohols } \\
\hline Father & 49 (32.5\%) & $20(13.2 \%)$ & $69(22.8 \%)$ \\
\hline Mother & $3(2.0 \%)$ & $1(0.7 \%)$ & $4(1.3 \%)$ \\
\hline Both & $9(6.0 \%)$ & $1(0.7 \%)$ & $10(3.3 \%)$ \\
\hline \multicolumn{4}{|l|}{ Khat chewing } \\
\hline Yes & 78 (51.7\%) & $22(14.6 \%)$ & 100 (33.1\%) \\
\hline No & $73(48.3 \%)$ & $129(85.4 \%)$ & 202 (66.9\%) \\
\hline \multicolumn{4}{|l|}{ Who chewing khat } \\
\hline Father & $39(25.8 \%)$ & $9(6.0 \%)$ & $48(15.9 \%)$ \\
\hline Mother & $3(2.0 \%)$ & & $3(1.0 \%)$ \\
\hline Both & $36(23.8 \%)$ & $13(8.6 \%)$ & $49(16.2 \%)$ \\
\hline \multicolumn{4}{|c|}{ Fear of medication cost } \\
\hline Yes & $64(42.4 \%)$ & $24(15.9 \%)$ & 88 (29.1\%) \\
\hline No & 87 (57.6\%) & $127(84.1 \%)$ & 214 (70.9\%) \\
\hline
\end{tabular}

Mother educational status was shown to be a determinant factor of delay in malaria prompt diagnosis and timely treatment in under-five children. Illiterate mothers were more likely to delay to present their children for prompt diagnosis and timely malaria treatment than whose educational statuses were above secondary school [AOR $=7.14$; 95\%CI: 1.10, 46.39]. This finding was supported by study conducted in Burkina Faso which showed that literacy level of mothers were the main factors to bring under five children within 24 hours to health facility for prompt diagnosis and timely malaria treatment [16]. 
Table 3. Variables associated with determinants of delay of prompt malaria diagnosis and timely treatment in under-five children in Shashogo woreda, Hadiya zone, Southern Ethiopia, May 2013 (n = 302).

\begin{tabular}{|c|c|c|c|c|c|}
\hline Variables & Cases number & Controls number & $\begin{array}{l}\text { Crude odds } \\
\text { ratio }(95 \% \mathrm{CI})\end{array}$ & $\begin{array}{l}\text { Adjusted odds } \\
\text { ratio }(95 \% \mathrm{CI})\end{array}$ & p-value \\
\hline \multicolumn{6}{|l|}{ Age of parents } \\
\hline $20-29$ & 48 & 98 & 1 & 1 & \\
\hline $30-39$ & 73 & 42 & $3.55(2.12,5.93)$ & $2.9(0.98,6.76)$ & 0.056 \\
\hline $40-49$ & 30 & 11 & $5.57(2.57,12.05)$ & $5.4(1.49,19.91)$ & 0.10 \\
\hline \multicolumn{6}{|l|}{ Mother's education } \\
\hline Illiterate & 63 & 15 & $27.3(5.56,134.1)$ & $7.14(1.10,46.39)$ & $0.039^{*}$ \\
\hline Read and write & 36 & 8 & $29.25(5.48,156)$ & $3.51(0.45,27.16)$ & 0.23 \\
\hline Primary school & 34 & 31 & $7.13(1.49,34.12)$ & $1.6(0.25,10.27)$ & 0.63 \\
\hline Secondary school & 16 & 84 & $1.24(0.16,6.02)$ & $0.66(0.11,3.98)$ & 0.65 \\
\hline Above secondary & 2 & 13 & 1 & 1 & \\
\hline \multicolumn{6}{|l|}{ Monthly income } \\
\hline$\leq 500$ & 88 & 19 & $12.5(6.72,23.34)$ & $5.49(2.09,14.45)$ & $0.001^{*}$ \\
\hline $501-999.9$ & 26 & 32 & $2.2(1.16,4.17)$ & $0.95(0.35,2.57)$ & 0.92 \\
\hline$\geq 1000$ & 37 & 100 & 1 & 1 & \\
\hline \multicolumn{6}{|l|}{ Sex of children } \\
\hline Female & 101 & 43 & $5.07(3.11,8.28)$ & $3.45(1.62,7.34)$ & $0.001^{*}$ \\
\hline Male & 50 & 108 & 1 & 1 & \\
\hline \multicolumn{6}{|l|}{ Distance } \\
\hline$\leq 3 \mathrm{~km}$ & 31 & 117 & 1 & 1 & \\
\hline $4-5 \mathrm{~km}$ & 98 & 22 & $16.8(9.15,30.90)$ & $3.5(0.62,32.26)$ & 0.21 \\
\hline$>5 \mathrm{~km}$ & 22 & 12 & $6.92(3.09,15.51)$ & $4.3(1.22,15.23)$ & $0.023^{*}$ \\
\hline \multicolumn{6}{|l|}{ History of child death } \\
\hline Yes & 19 & 29 & 1 & 1 & \\
\hline No & 132 & 122 & $1.65(0.881,3.09)$ & $4.21(1.52,11.68)$ & $0.006^{*}$ \\
\hline \multicolumn{6}{|l|}{ Fear of side effect } \\
\hline Yes & 54 & 32 & $2.07(1.24,3.46)$ & $2.91(1.15,7.33)$ & $0.024^{*}$ \\
\hline No & 97 & 119 & 1 & 1 & \\
\hline \multicolumn{6}{|l|}{ Khat chewing } \\
\hline Yes & 78 & 22 & $6.27(3.60,10.89)$ & $2.38(1.28,5.79)$ & $0.05^{*}$ \\
\hline No & 73 & 129 & 1 & 1 & \\
\hline
\end{tabular}

"Significant by both bivariate and multivariate logistic regression at p-value $<0.05$.

Average monthly income was other determinant of delay of prompt malaria diagnosis and timely treatment in under-five children. Parents who had monthly income 500 ETB and below were more likely delay to get their children for prompt diagnosis and timely malaria treatment than who had 1000 ETB and above [AOR = 5.49; 95\%CI: 2.09, 14.45]. This could be explained as having more income could motivate parents to bring their children for early diagnosis and treatment of malaria and also those who had better income could have a better access to health facility.

Distance from health centers was found to be a determinant of delay of prompt malaria diagnosis and timely treatment for under-five children. Mothers/caretakers who lived in village five kilometers or more away from health centers were more likely to be late to seek malaria treatment for under-five children than those who lived in a village near to health facility three kilometers or less [AOR $=4.3$; 95\%CI: 1.22, 15.23]. This finding was supported by studies done in Southwest Ethiopia, Yemen, and India [15] [17] [18]. This might be due to the accessibility of heath facility nearer to the village, which may increase the frequency of visit and create awareness 
to early diagnosis and timely malaria treatment seeking.

In this study, having no history of child death in the family was shown to be a determinant of delay of prompt malaria diagnosis and timely treatment for under-five children. Parents who had no history of child death were more likely to late to bring their children promptly for malaria diagnosis and treatment than those who had history of child death in the family [AOR $=4.21$; 95\%CI: 1.52, 11.68]. This finding was in line with study done in Southwest Ethiopia [15]. This could be due to previously happened death and severity of the illness might change treatment seeking behavior of the parents.

Mothers/caretakers who complained about side effect of antimalarial drugs were more likely to delay to bring their children for prompt malaria treatment than those who didn't complained about the side effects of antimalarial drugs prescribed by health personnel before the illness of the current child [AOR $=2.07 ; 95 \% \mathrm{CI}: 1.15$, 7.33]. This might be due to lack of proper counseling and education during prescribing drugs, those mothers/ caretakers who complained might assume that the side effects of anti-malarial drugs are harmful than its benefits.

In this study, khat chewing was found to be a determinant of delay of prompt malaria diagnosis and timely treatment for under-five children. Parents who chewed khat were more likely to be late to seek prompt malaria treatment for their children than those who didn't chew khat [AOR $=2.38$; 95\%CI: 1.82, 5.79]. This might be explained as khat chewing affects the economical status of the study participant, this in turn affects prompt malaria diagnosis and timely treatment of under five children.

This study revealed that sex of the child was shown an effect on delay of prompt malaria diagnosis and timely treatment. Parents of female child were more likely to delay to bring their children for prompt diagnosis and timely treatment than of male child [AOR $=3.45$; 95\%CI: 1.62, 7.34]. This finding was supported by study done in Kenya, Nairobi which stated boys were more likely to get early diagnosis and treatment of malaria than girls [19]. The main reason could be due to cultural influence and gender inequality in the community.

Even though this study has identified many determinants in malaria prompt diagnosis and timely treatment it was not free of biases due to recall of the study participant the exact days of onset of signs and symptoms of their children.

\section{Conclusion}

The finding of this study identified that mother's education, monthly income, sex of child, distance from the health centers, having no history of child death, complain about side effects of anti-malarial drugs and khat chewing were found to be determinant factors of delay in malaria prompt diagnosis and timely treatment in under-five children. Effective malaria control programs revision would be required to avoid delay of prompt diagnosis and timely treatment for under-five children.

\section{Acknowledgements}

First of all we would like to extend our gratitude to Hossana College of Health Sciences for their financially support. We also like to extend our appreciation to University of Gondar, institution of public health for providing us ethical clearance. Lastly, our acknowledgement goes to Shashogo woreda health office, Heads of health centers, study participants and data collectors for their valuable contribution in the realization of this study.

\section{Competing Interests}

The authors declare that they have no competing interests.

\section{Authors' Contributions}

Ermias Abera, wrote the proposal, participated in data collection, analyzed the data and drafted the paper. Kassahun Alemu and Teresa Kisi approved the proposal with some revisions, participated in data analysis and revised subsequent drafts of the paper. All authors read and approved the final manuscript.

\section{References}

[1] WHO (2010) Guidelines for the Treatment of Malaria. 2nd Edition. 
[2] Greenwood, B.M., Bojang, K., Whitty, C.J. and Targett, G.A. (2005) Malaria. Lancet, 365, 1487-1498. http://dx.doi.org/10.1016/S0140-6736(05)66420-3

[3] WHO (2011) Global Malaria Programmes. World Malaria Report 2011.

[4] US Global Health Policy (2011) The Global Malaria Epidemic.

[5] Maslove, D.M., Mnyusiwalla, A., Mills, E.J., McGowan, J., Attaran, A. and Wilson, K. (2009) Barriers to the Effective Treatment and Prevention of Malaria in Africa: A Systematic Review of Qualitative Studies. BMC International Health and Human Rights, 9, 26. http://dx.doi.org/10.1186/1472-698X-9-26

[6] Roll Back Malaria (2005) Global Strategic Plan 2005-2015.

[7] Chanda, P., et al. (2011) Community Case Management of Malaria Using ACT and RDT in Two Districts in Zambia: Achieving High Adherence to Test Results Using Community Health Workers. Malaria Journal, 10, 158. http://dx.doi.org/10.1186/1475-2875-10-158

[8] Onwujekwe, O., et al. (2011) Do Poor People Use Poor Quality Providers? Evidence from the Treatment of Presumptive Malaria in Nigeria. Tropical Medicine and International Health, 16, 1087-1098. http://dx.doi.org/10.1111/j.1365-3156.2011.02821.x

[9] Gilbert, K. (2009) Ongoing Challenges in the Management of Malaria. Malaria Journal, 8, S2. http://dx.doi.org/10.1186/1475-2875-8-S1-S2

[10] The Carter Center (2012) Summary Proceedings, 3rd Annual malaria Control Program Review. The Carter Center at Atlanta.

[11] Federal Ministry of Health, Ethiopia (2012) National Malaria Guidelines. 3rd Edition, Addis Ababa.

[12] Ministry of Health, Ethiopia (2007) Entomological Profile of Malaria in Ethiopia. African Network on Vector Resistance. WHO/Regional Office for Africa.

[13] WHO/CDS/RBM (2000) The Abuja Declaration on Roll Back Malaria in Africa by the African Heads of State and Governments. Abuja.

[14] RBM (2005) Global Strategic Plan. Roll Back Malaria 2005-2015. Roll Back Malaria Partnership, Geneva.

[15] Getahun, A., et al. (2010) Determinants of Delay in Malaria Treatment Seeking Behaviour for Under-Five Children in South-West Ethiopia: A Case Control Study. Malaria Journal, 9, 320. http://dx.doi.org/10.1186/1475-2875-9-320

[16] Tipke, M., Louis, R.V. and Yé, M. (2009) Access to Malaria Treatment in Young Children of Rural Burkina Faso. Malaria Journal, 8, 266. http://dx.doi.org/10.1186/1475-2875-8-266

[17] Al-Taiar, A., et al. (2008) Who Develops Severe Malaria? Impact of Access to Healthcare, Socio-Economic and Environmental Factors on Children in Yemen: A Case-Control Study. Tropical Medicine and International Health, 13, $762-$ 770. http://dx.doi.org/10.1111/j.1365-3156.2008.02066.x

[18] Das, A. and Ravindran, T.S. (2010) Factors Affecting Treatment-Seeking for Febrile Illness in a Malaria Endemic Block in Boudh District, Orissa, India: Policy Implications for Malaria Control. Malaria Journal, 9, 377. http://dx.doi.org/10.1186/1475-2875-9-377

[19] Taffa, N. and Chepngeno, G. (2005) Determinants of Health Care Seeking for Childhood Illnesses in Nairobi Slums. Tropical Medicine and International Health, 10, 240-245. http://dx.doi.org/10.1111/j.1365-3156.2004.01381.x 